\title{
Factors Influencing the Stability and Quality of the French ED Surveillance System
}

\author{
Isabelle Pontais*, Vanina Bousquet, Marc Ruello, Céline Caserio-Schönemann and \\ Anne Fouillet
}

French Institute for Public Health Surveillance, Saint-Maurice, France

\section{Objective}

Identification of the main factors influencing the stability and the quality of the French Emergency departments (ED) syndromic surveillance system.

\section{Introduction}

Since 2004, the French syndromic surveillance system Oscour ${ }^{\circledR}$ has been implemented by the national institute for public health surveillance (InVS) and is daily used to detect and follow-up various public health events all over the territory [1].

Beginning with 23 ED in 2004, the coverage and data quality have permanently been increasing until including about 650 ED in August 2015. Initially based on a voluntary participation of ED, a mandatory transmission has been decided in July 2013, with major modification on the structural organization of the data transmission in some regions and on coding practices of the new ED.

Besides this juridical context, the system is based on automatically data collection by ED physicians without recording added information for public health surveillance. This represents the main theorical condition to ensure stability and quality, even in case of occurrence of major public health events susceptible to drastically increase the workload [2].

\section{Methods}

Four evaluation criteria on essential characteristics for a syndromic system were daily supervised during 19 consecutive months (from May 2014 to November 2015) through a dashboard [3]:

$1 /$ stability and 2/regularity of data transmission at D+1 (expected delay), evaluated by a prospective calculation of the proportion of $\mathrm{ED}$ having transmitted their data on time,

3 / the data transmission delay during a 7-day period, when data are not transmitted at $\mathrm{D}+1$,

4/ the data quality of medical information (ICD10 codes)

Three main factors influencing these criteria have been analyzed: 1 / temporal factors (day of week, day-off, vacations), 2 / health events occurring in 2015 (the exceptional influenza epidemic from January to March and a major heat wave in July), 3/ the influence to move from a voluntary to a mandatory system on data quality and transmission.

\section{Results}

Every day, about 40,000 attendances recorded in 550 ED are transmitted to InVS, corresponding to $82 \%$ of the total number of attendances expected from the ED including in the network. From May 2014 to August 2015, this number increase of $27 \%(+12,000$ attendances) due to the introduction of 150 new ED related to the move to a mandatory system (Figure 1).

From May to September 2014, major instability was observed in data transmission, correlated with these numerous new ED. Since autumn 2014, the part of attendances transmitted on time presents daily variation from 80 to $90 \%$. No difference is noted in the number of ED transmitting data between days of week and week-end. Variations are essentially due to technical problem in the ED or in the regional platform centralizing the ED data for the whole region.
In 2015, the two major health events occurring in France did not impact negatively the data transmission (Figure 1).

The impact of the move to a mandatory system is currently analyzing.

\section{Conclusions}

The setting-up of the daily analysis of data transmission indicators allowed identifying frailty issues. Efficient solutions with IT unit and ED were implemented, enabling a better stability and regularity in a 3-months delay.

Finally the follow-up of such indicators in routine is an added-value for the reactivity of actions when technical difficulties occur. It is also crucial for supporting the epidemiological analysis and interpretation of data. Such indicators are included in the daily bulletins and dashboards published weekly at national and regional levels.

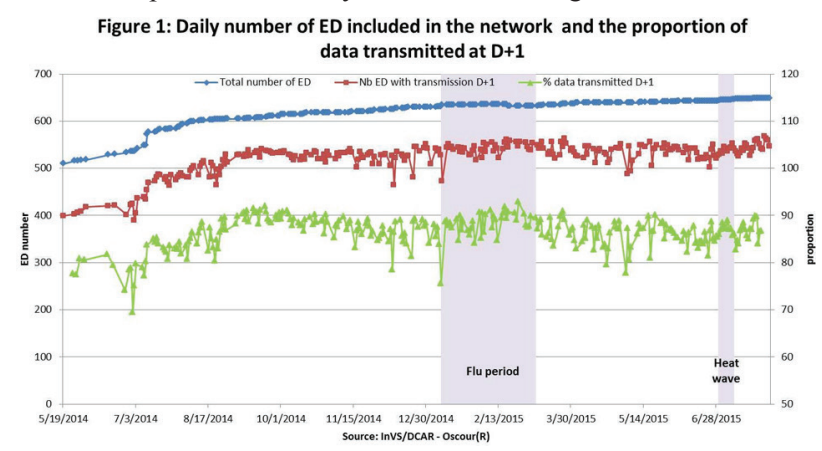

\section{Keywords}

Evaluation analysis; syndromic system; OSCOUR system; Lesson learned

\section{Acknowledgments}

To emergency department data providers and all InVS regional unit for their substantial contribution to the system.

\section{References}

[1] Josseran L, Nicolau J, Caillère N, Astagneau P, Brücker G. Syndromic surveillance based on emergency department activity and crude mortality: two examples. Euro Surveill 2006;11:225-9.

[2] Caserio-Schönemann C, Bousquet V, Fouillet A, Henry V. Le système de surveillance syndromique SurSaUD (R). Bull Epidémiol Hebd 2014;3-4:38-44.

[3] Fouillet A, Bousquet V, Pontais I, Gallay A and Caserio-Schönemann C. The French Emergency Department OSCOUR Network:Evaluation After a 10-year Existence. Online Journal of Public Health Informatics ISSN 1947-2579 -7(1):e74, 2015

\section{*Isabelle Pontais}

E-mail: i.pontais@invs.sante.fr 